\title{
OS ARCANOS DA EPIGRAFIA
}

\author{
Mauro $W$ Quintino de Almeida
}

Que interesse podem ter rabiscos feitos sobre monumentos há 2.000 anos? - perguntaria alguém. No entanto, inscrições como a da família de Preneste (1), a mais antiga inscrição latina ( \pm 600 a.C.), nos informam muito sobre a história da língua dos romanos; a Tábua Claudiana de Lyon (2), comparada com passo de Tácito que trata de igual assunto (3), nos ensinas sobre a política e a eloquiência do Imperador Cláudio ao mesmo tempo que nos esclarece sobre os métodos do grande Historiador Basta pensar-se em monumentos como o código de Hammurabi ou a pedra de Rosette ou mesmo os graffiti de Pompéia para que se aceite, sem dificuldade, que a Epigrafia dá contribuições valiosas ao desenvolvimento do saber e à história do homen sobre a terra.

Não se vai discutir aqui a diferença que passa entre Epigrafia, Paleografia, Diplomática e Edótica, já feita noutro lugar por notável especialista (4) $\mathrm{O}$ que se pretende é mostrar o tratamento que se pode dar a um texto epigráfico e por em evidência os ensinamentos que ele pode apresentar. Por questão de didática, o nosso estudo será dividido nos itens seguintes: a inscrição, a transcrição, a tradução e os comentários dessa inscrição.
$\mathrm{A}-\boldsymbol{A}$ inscrição
Q. ANTISTIO ADVENTO
Q. F. QVIR. POSTVMO. AQVI

(1) - Sobre essa inscrição podem-se encontrar pormenores em ERNOUT, A., Recueil de textes archä̈ques latins, Paris, Klincksieck, 1916, p. 3-4 (texto $\mathrm{n}^{\circ}$ 1) que, por sua vez, a transcreve do Corpus Inscriptionum Latinarum (C. I. L.), I $\mathbf{I}^{2}, 3$.

(2) - C. I. L., XIII, 1668. Foi encontrada no século XVII, em Lyon, França. Depositada, primeiramente, no museu da cidade (Musée St.

Pierre), foi levada, depois, para Paris onde se encontra atualmente (Musée du Louvre)

(3) - Annales, XI, 23-25.

(4) - SPINA, Segismundo, Introdução à Edótica, São Paulo, Cultrix /EDUSP, 1977, p. 17 e segs. 
LINO. COS. SACERDOTI FETI

ALI. LEG. AVG. PR. PR. PROVINC. GER

MANIAE INFERIORIS. LEG. AVG.

AT PRAETENTVRAM ITALIAE ET

ALPIVM EXPEDITIONE GERMA

NICA CVRA. OPERVM LOCORVMQ.

PVBLICORVM LEG. AVG. PR. PR.

PROVINC. ARABIAE LEG. AVG. LEG

VI FERRATAE ET SECVNDAE AD

IVTRICIS TRANSLATO IN EAM EX

PEDITIONE PARTHICA QVA DONA

TVS EST DONIS MILITARIBVS

CORONIS MVRALI VALLARI AV

REA HASTIS PVRIS TRIBVS VE

XILLIS DVOBVS PRAETORI LEG

AVG. PR. PR. PROVINC. AFRICAE TR. PL.

SERVIRO EQ.R. Q. PR. PR.PROVINC.

MACEDONIAE TRIBVNO MIL.

LEG. I. MINERVIAE P. F. IIII VIR

VIARVM CVRANDARVM

SEX. MARCIVS MAXIMVS OB IN

SIGNEM EIVS IN SE BENIVOLEN

TIAM S.P.P.D.D. (5)

B - A transcrição

$\mathrm{Q}$ (uinto). ANTISTO. ADVENTO/Q(uinto) F(ilio) QVIR(ina tribu) POSTVMO. AQVI/LINO. CO $(n)$ S $(u l i)$ SACERDOTI. FETI/ALI. LEG(ato) AVG (usti). PR(o) PR(aetore) PROVINC(iae) GER/MANIE. INFERIORIS. LEG(ato) AVG(usti)/ AT/PRAETENTVRAM. ITALIAE. ET/ALPIVM. EXPEDITIONE. GERMA/NICA. CVRA(tori) OPERVM. LOCORVMO(ue)/ PVBLICORVM. LEG(ato) AVG(usti) LEG(ionis)/(sextae) FERRATAE. ET SECVNDAE. AD/IVTRICIS. TRANSLATO. IN EAM. EX/PEDITIONE. PARTHICA. QVA. DONA/TVS. EST DONIS. MILITARIBVS/CORONIS. MVRALI. VALLARI. AV/REA. HASTIS. PVRIS. TRIBVS. VE/XILLIS. DVOBVS. PRAETORI. LEG(ato)/(AVG(usti) PR(o) PR(aetore) PROVINC(iae) AFRICAE. TR(ibuno) PL(ebis)/(ebis)/SEVIRO. $\mathrm{EQ}$ (uitum) $\mathrm{R}$ (omanorum) $\mathrm{Q}$ (u, restori) $\mathrm{PR}($ o) $\mathrm{PR}$ (aetore) PROVINC(iae) MACEDONIAE. TRIBVNO. MIL(itum)/LEG(ionis) (primae) MINERVIAE. P(iae) $\mathbf{F}$ (idelis) (uattuor) VIR(o)/VIARVM. CVRANDARVM/SEX(tus) MARCIVS. MA-

(5) - C. I. L., VIII, 18893 bis. 
XIMVS. OB. IN/SIGNEM. EIVS. IN SE. BENIVOLENTIAM. $\mathbf{S}$ (ua) $\mathbf{P}$ (ecunia) $\mathbf{P}$ (osuit) $\mathbf{D}$ (ecreto) $\mathbf{D}$ (ecurionum)

$$
\text { C - A tradução }
$$

A Quinto Antístio Advento Póstumo Aquilino, filho de Quito, pertence à tribo Quirina,

- cônsul,

- sacerdote fecial,

- legado imperial propretor da província da Germânia inferior,

- legado imperial para a guarnição da fronteira da Itália e dos Alpes durante a expedição germânica,

- curador dos trabalhos e dos lugares públicos,

- legado imperial protetor da província da Arábia,

- legado imperial da sexta legião, chamada Ferrata, e da segunda, chamada Adiutrix (6), transferido para esta durante a expedição com condecoração militares, isto é, uma coroa mural, uma coroa valar, uma coroa de ouro, três lanças puras, dois estandartes,

- pretor,

- legado imperial propretor da província da Africa,

- tribuno da plebe,

- séviro dos cavaleiros romanos,

- questor propretor da província da Macedônia,

- tribuno militar da primeira legião, dita Minervia, Pia, Fidelis (7),

- quatuórviro encarregado da manutenção das estradas, Sexto Márcio Máximo, pela notável estima de Aquilino para com a sua pessoa, por decreto dos decuriões, mandou construir este monumento às suas espensas.

$\mathrm{D}$ - Os comentários

Trata-se de uma inscrição honorária inscrita num monumento consagrado a Quinto Antístio advento Póstumo Aquilino por Sexto

(6) - Ferrata: protegida com ferro, com couraça; Adiutrix: auxiliar.

(7) - Mineruia: consagrada à deusa Minerva; Pia: devotada, dedicada; Fidelis: leal.

(7) - bis Friedrich STOLZ (Historia de la langua latina, trad. de Juan-Bautista Sita-Aquino Anjou, México, Unión Tipográfica Editorial Hispano-Americana [UTEHA], 1961, p. 59 (\$83), citando W. SCHULZE, observa que a denominação das pessoas pelos tria nomina é, provavelmente, um costume de origem etrusca. 
Márcio Máximo. Este quis as:m agradecer algum notável favor recebido de Aquilino, talvez durante a sua legação imperial como propretor na província da África.

Temos aqui um CVRSVS HONORVM senatorial em ordem inverso. O comentário que dele faremos será dividido em duas partes: consideraremos, primeiramente, os elementos que se referem à onomástica e, depois, os elementos que fazem parte do CVRSVS propriamente dito.

\section{I - Quanto à onomástica}

Os romanos se serviam geralmente de três palavras para designar um indivíduo. A primeira era o praenomen (prenome), a segunda o nomen (nome [gentílício]) e a terceira o cognomen ("sobrenome", nome que vinha depois do nome gentilício) $\mathrm{O}$ apelido ou alcunha (signum, uocabulum), embora existente entre os romanos, só aparece nas inscriçōes pela metade do II século d.C. (8)

1 O praenomen era um meio que havia para se distinguirem as pessoas pertencentes à mesma gens. Primeiramente, ele teve um sentido bem particular, isto é, dizia respeito sempre a um pormenor da vida do recém-nascido. Assim, Manius, por exemplo, designava as crianças nascidas de manhã (MANE); Lucius, as que vinham ao mundo ao romper da luz (LUX) Não era extensa a lista dos prenomes romanos: uns 30, se se der crédito ao autor anônimo do Liber de praenominibus. :

Gentilicia nomina Varro putat fuisse numero mille, praenomina circa triginta.

[Varrão pensa que os nomes gentilícios foram em número de mil; os prenomes cerca de 30] (9).

No nosso caso, QVINTVS traz o mesmo pronome que o pai. Não se trata, portanto, como poderia crer-se do $5^{\circ}$ filho de uma série de cinco.

Deve-se observar ainda que o prenome era dado ao recém-nascido no nono dia depois do nascimento. Parece ser esse um costume bastante divulgado, pois podemos encontrá-lo entre os judeus (10) Muito embora recebesse a criança o seu prenome poucos dias depois de nascer, este, no entanto, não era inscrito na lista do censo senão após a tomada da toga viril.

(8) - CAgNAT, René, Cours d'Epigraphie latine, Paris, E. de Boccard, 1914, p. 55.

(9) $-\S 3$.

(10) - Luc., I, 59-61; Gn., XVII, 12; Lv., XII, 3. 
Num texto epigráfico, o prenome vinha sempre escrito abreviadamente e sempre à testa de todas as outras palavras que indicavam a identidade de um indivíduo.

2. ANTISTIVS é o nomen gentilicium do nosso personagem. Essa parte do nome servia para dividir os cidadãos em grupo ou gentes. Traziam-no também os escravos e libertos. Contrariamente ao que acontecia com o pronome, vinha escrito por extenso. Além disso, tinha a particularidade de acabar quase sempre em - IVS.

3. Depois do prenome e do nome, vinha o "sobrenome" (cognomen), que era separado dos primeiros pela designação da filiação e da tribo. No início, era constituído por só palavras, quase sempre um adjetivo, que tinha uma significação real a partir de uma particularidade física: $B A R B A T V S$ (o que trazia barba [de barba]), AENOBARBVS (o que tinha barba cor de cobre [de aenus, cobre, e barba]), CICERO (do grego: grão-de-bico - devia referir-se a algum sinal físico com essa forma), NASICA (aquele que tem o nariz fino e pontudo [de nasus, nariz]) e outros "sobrenomes" que tais. O cognomen servia para distinguir as pessoas de uma gens assim como as divisões e subdivisões de uma mesma gens. É assim que temos como pertencentes à gens CORNELIA, os Cornelii Balbi, os Cornelii Scipiones e os Cornelii Scipiones $N$ a si ca e que é uma subdivisão do ramo dos Cornelii Scipiones. Depois, tornou-se costume tomar aos próprios antepassados os seus nomes gentilícios quando não os seus prenomes ou "sobrenomes" E por isso que se podem encontrar vários prenomes, nomes ou "sobrenomes" pertencendo a uma só pessoa. Digno de nota é o caso daquele indivíduo que aparece no Corpus Inscriptionum Latinarum (11), cônsul em 169 d. C., com P(úblico) Celso Apolinário (12): os seus "sobrenomes" ultrapassam a casa dos 30:

Q(uintus) Pompeius [Quinti Pompeii filius, Quirina tribu] Senecio Roscius Murena Coelius Sextus Iulius Frontinus Silius Decianus Caius Iulius Eurycles Herculaneus Lucius Vibullius Pius Augustanus Alpinus Bellicius Sollers Iulius Aper Ducenius Proculus Rutilianus Rufinus Silius Valens Valerius Niger Claudius Fuscus Saxa Urytianus Sosius Priscus.

Os ibero-americanos têm, de sobre, como explicar a sua tradição e gosto pelo acúmulo de nomes e sobrenomes. Em faltando as razões de nobreza de raiz, uma série de nomes grandiloqüentes lhe faziam (e fazem ainda) as vezes. Segundo CAGNAT (13) todos os compo-

(11) - XIV, 3609.

(12) - GOYAU, Georges, Chronologie de l'Empire romain, Paris, Klincksieck, 1891, p. 221.

(13) - op. cit., p. 53 e 54. 
nentes de uma série de nomes como essa devem ser considerados "sobrenomes". No caso presente, têm-se ADVENTVS POSTMVS AQVILINVS, um conjunto de três palavras para designar-se o cognomen de Quintus Antistius. Normalmente, por causa do lugar onde se encontra, isto é, antes da designação da filiação e da tribo, podiam-se considerar também as palavras ANTISTIVS ADVENTVS como um nome gentilício composto. No entanto, consoante CAGNAT (14) e porque DEGRASSI (15) admite ANTISTIVS como o único nomen gentilicium possível, somos então levados a dizer que aqui se trata antes de um "sobrenome" composto de vários cognomina. Destes o mais significativo, o mais conhecido, o mais expressivo era AQVILINVS que, à maneira de uma alcunha, identificava melhor o nosso personagem por causa talvez de uma particularidade física que não passa despercebida como um nariz com uma forma um pouco exagerada, curvo como uma unha de águia (AQVILINVS vem de AQVILA).

4. Quinti filio. - E a indicação da filiação. Tinha um papel muito grande durante o tempo em que não havia ainda o cognomen. Servia para fazer a diferença dos membros de uma mesma gens. Quando o "sobrenome" apareceu, a indicação da filiação perdeu o valor de meio de identificação. Mesmo assim, porém, foi conservada.

Materializava-se através da palavra filius (F), em apoção, precedida apenas do prenome do pai no genitivo (Quinti) As vezes a palavra filius era suprimida nas incrições da Espanha ou da Âfrica, se o pai da pessoa aí comemorada tinha um praenomen indígena. Ora, esta inscrição era da África, de Thibilis (16) Então Antistius Aquilinus era filho de um cidadão romano de nascimento ou naturalizado visto que a palavra filius aí aparece.

Enfim, observe-se ainda que Antistius Aquilinus não era filho natural porque aí está citado o prenome do pai e não apenas o nome gentilício da mãe. Aqui está a origem bem longínqua do hábito vigente entre nós até pouco tempo de se exagerarem certidões (de nascimento, de batismo) de um filho natural fazendo-se constar apenas o nome da mãe. Como se não bastasse, ainda se acrescentava a expressão "filho natural de", assaz degradante socialmente, que, em boa hora, foi eliminada.

5 Quirina tribu.- Desde o reinado de Sérvio Túlio a ciuitas romana tinha sido dividida em tribos à imitação, talvez, dos dêmoi

(14) - idem, ibidem.

(15) - I fasti consolari, Roma, 1952, p. 244.

(16) - GAFFIOT (Dictionnaire illustre latin-français, Paris, Hachette, 1936, p. 1574, s.v Tibilis [thibilis]) aponta essa cidade - hoje Announa como sendo da antiga Numídia, região que corresponde em parte à Argélia atual. 
da Grécia. $O$ número de tribos atingiu apenas a casa dos 35 e não mais.

A indicação da tribo num texto epigráfico era um elemento a mais que ajudava a identificar um indivíduo. Mas durante a expansão do Império Romano, as cidades que obtinham o direito de cidadania tomavam o nome de uma entre as 35 tribos. No tempo do Império, então, a indicação da tribo perdeu o seu valor real.

O nome da tribo vinha sempre abreviado e era dificilmente escrito por extenso. Neste último caso, era posto no caso ablativo e a palavra $\operatorname{tr}$ i $b u$ (ablativo) ficava subentendida. Ocupava lugar sempre depois da filiação e antes do "sobrenome" (cognomen) Quando havia vários "sobrenomes", principalmente nos textos egigráficos da África, a filiação e a indicação da tribo eram colocadas depois do primeiro congnomen, como acontece aqui.

Essas, as observações a respeito da onomástica. A seguir, examinaremos os elementos referentes ao CVRSVS HONORVM.

\section{II - Quanto ao CVRSVS HONORVM}

Como se trata de um CVRSVS HONORVM senatorial em ordem inversa, propomo-nos comentar a inscrição partindo das magistraturas mais humildes e chegarmos depois às magistraturas mais elevadas.

1 Quatuoruiro uiarum curandarum. - Antes de se chegar ao primeiro degrau do CVRSVS HONORVM, era preciso passar-se de início por funções pré-questiorianas: o vigintivirato e o tribunato militar. O vigintivirato era a reunião de 20 homens (viginti), distribuídos da maneira seguinte:

a) $X$ uiri stlitibus iudicandis ( $X V . S T L . I V D$.$) : que eram en$ carregados dos processos civis (lis, litis: processo) relativos ao direito de cidadania;

b) III uiri monetalos (III V.MON) ou auro argento aere flando feriundo (A.A.A.F.F ): que eram encarregados da cunhagem de moda;

c) III uiri kapitales (III V.KAP ): aos cuidados de quem ficavam as execuções capitais (caput, capitis: cabeça);

d) IIII uiri uiarum curandarum (IIII V V CVR.): encarregados da manutenção das vias públicas. A duração da função era de um ano. Antistius Aquilinus fez parte deste último grupo.

2. tribuno militum legionais primae Mineruiae, Piae, Fidelis.O tribunato militar era o serviço militar de nossos dias. Durava em 
princípio um ano. Entretanto, a presença obrigatória era apenas de seis meses.

Podemos notar que Antistus Aquilinus foi tribuno depois de ter passado pelo vigintivoirato. Isso acontecia depois da época dos Flávios. Aí está um elemento precioso porque nos ajuda a datar a inscrição.

Enfim, a primeira legião, com a trigésima, dita Ulpia estava aquartelada na Germânia inferior (17)

3. quaestori pro praetore prouinciae Macedoniae.- Aqui temos o primeiro degrau da carreira senatorial. Era preciso ter 25 anos no mínimo. Na época imperial havia 20 questores:

a) 2 questores imperiais (quaestor Imperatoris: Q. IMP; Caeasris: CAES; Augusti:AVG.): tinham o encargo de ler as mensagens do Imperador diante do Senado, fazendo-lhe as vezes;

b) 2 questores urbanos (quaestor urbanus: Q. VRB.): eram lotados nas finanças públicas como tesoureiros do Senado;

c) 4 questores dos cônsules (quaestores consulum: Q. COSS. ): cada cônsul tinha dois que o substituíam nos assuntos entre o Senado e o Imperador;

d) enfim, 12 questores com autoridade de pretor (quaestor pro praetore: Q.PR.PR.): eram enviados à província para aí exercer funções de caráter financeiro. Antístio foi um questor propretor.

Os questores entravam em função em 5 de dezembro de cada ano permanecendo no cargo até 4 de dezembro do ano seguinte.

4. seuiro equitum Romanorum.- Por vezes, os futuros questores eram convidados a exercer as funções de séviro antes de chegar à questura. O sevirato consistia em ser alguém o chefe de uma das turmas de cavaleiros romanos que desfilavam diante do Imperador em 13 de julho. Trata-se de um título honorífico. Aqui normalmente vem uma função questoriana. O nosso personagem, no entanto, foi séviro depois da questura.

5 tribuno plebis.- É o segundo degrau do CVRSVS HONORVM senatorial o tribunato da plebe ou a edilidade. Os jovens patrícios podiam ser somente edis curuis e, às vezes até eram chamados à pretura antes da questura. Os plebeus, pelo contrário, não podiam ter acesso à pretura antes de ter exercido o tribunato da plebe. Vê-se

(17) - HENZEN, G., \& DE ROSSI, I. B., Inscriptiones Vrbis Romae Latinae, Berlin, 1876, Vol. VI, 3492 a \& b. Vlpia: que diz respeito a Ulpio Trajano, imperador romano. 
então, que o nosso personagem era de origem plebéia. A duração do tribunato era de um ano.

6. legado Augusti pro praetore prouinciae Africae - Depois da questura, o uir quaestorius podia exercer funções ditas questorianas, sempre em província, com exceção da África onde, de modo geral, é um antigo pretor (uir praetorius) que é ligado. Estamos, portanto, diante de uma exceção.

A duração da legação era de um ano. O mês de julho era o fixado para o início do exercício.

Havia dois tipos de províncias: nições;

A) províncias senatoriais: pacificadas e desprovidas de guar-

B) províncias imperiais: estas eram providas de guarnições.

As províncias senatoriais se subdividiam em:

a) consulares: que eram confiadas a procônsules; e

b) pretorianas: que eram governadas por uiri praetoril.

As províncias imperiais se subdividiam também em:

a) consulares: guarnecidas com várias legiões, confiadas a legati Augusti pro praetore, que eram antigos cônsules, assistidos por 3 legados e 1 questor; e

b) procuratorianas: que fazem parte do domínio pessoal do Imperador. São administrados por prefeitos ou por procuradores da classe equestre.

Aquilino era um legado proconsular de uma província senatorial consular.

7 praetori.- A pretura era o terceiro degrau do CVRSUS HONORVM. Era exigida a idade de 300 anos no mínimo.

Havia vários tipos de pretores:

a) praetor urbanus ( $\mathrm{P}$ V ): devia encarregar-se dos problemas judiciários que diziam respeito apenas aos cidadãos romanos da cidade e de um raio de 100 milhas à volta de Roma;

b) praetor peregrinus (P.PER.): ocupava-se, como a palavra peregrinus o indica, dos problemas ligados aos estrangeiros;

c) praetor tutelarius (P. TVTEL.): cuidava das sucessões;

d) praetor hastarius (P.HAST.): era o presidente do centunvirato; trazia a lança (hasta) como emblema; 
e) praetor aerarii (P.AER. ): devia zelar pelo tesouro do Estado (aerarium Saturni) ou pelo tesouro militar (aerarium militare) Havia dois praetores aerarii e a função era do mesmo escalão.

Segundo a presente inscrição não podemos saber a que tipo de pretura Antistius Aquilinus pertencia.

8. legado Augusti legionis sextae Ferratas et secundas Adiutricis, translato in eam expeditione Parthica qua donatus est donis militaribus: coronis murali, uallari, aurea, hastis puris tribus, uexillis duobus. - O antigo pretor podia ser nomeado para exercer certas funções, ditas pretorianas, quer na província, quer em Roma ou na Italia. Nesta inscrição podemos ver duas delas. A primeira é precisamente esta: a legação legionária da VI legião durante a expedição pártica. A VI legião, com a X, chamada Fretensis (18), ficava aquartelada na Judéia (Syria Palaestina) Trata-se aqui de uma revolta que se deu entre 163-166, na Armênia, quando Aquilino, pela sua bravura, recebeu condecorações militares. Dessas havia dois tipos: para os soldados, subtenentes e aspirantes: armillae (braceletes), torques (colar) e phalerae (fáleras); e para os oficiais superiores: coronae (coroas), hastae purae (lanças puras) e uexillae (estandartes) Os legados legionários tinham direito a 3 coronae, 3 hastae purae e 3 uexillae. Vemos que o nosso personagem foi recompensado com 3 coroas: uma mural, que se dá a quem por primeiro transpõe o muro da cidadela inimiga; uma valar, que se dá a quem por primeiro transpõe uma trincheira e uma coroa de ouro, que se dá a quem salva um cidadão romano. Aquilino, na qualidade de pretoriano (uir praetorius) que era, tinha direito a 3 lanças puras, 3 coroas estandartes. Entretanto, vemos que ele foi galardoado apenas por 2 estandartes em vez de três.

9. legado Augusti pro praetore prouinciae Arabiae.- Essa é a segunda função pretoriana: a legação imperial com poderes de pretor (pro praetore) da Arábia, uma província imperial pretoriana.

10. curatori operum locorumque publicorum.- A curatela das obras e dos lugares públicos, com duração indeterminada, podia pertencer tanto às funções pretorianas como às consulares. Consoante este texto, não sabemos se Aquilino foi curador como uir praetorius ou como uir consularis (antigo cônsul)

11 consuli.- Aqui temos o quarto degrau do CVRSVS HONORVM senatorial, a dignidade suprema: o consulado. Era preciso ter no mínimo 33 anos. Outra exigência era a de se deixarem

(18) - Fretensis: que diz respeito a estreito (fretum: estreito). 
transcorrer 2 anos depois da pretura para se poder aspirar a essa dignidade.

Havia dois tipos de cônsules:

a) Consul ordinarius (COS.ORD.) Dois cônsules ordinários eram designados no ano que precedia e entravam em exercício em 19 de janeiro. A partir do dia da designação eram cônsulos designados: consul designatus (COS.DES.)

b) além d'sso, havia vários cônsules suplentes: consul suffectus (COS.SVFF ) Eram empregnados na administração e sucediam-se por grupos de dois, após um número não fixado de meses. Segundo DEGRASSI (19), o nosso personagem foi cônsul suplente en $166 \mathrm{~d}$.C.

Observe-se, enfim, que o consulado, a dignidade suprema, vem sempre no início da inscrição tanto se trate de um CVRSVS HONORVM em ordem inversa como de um em ordem direta.

12. legato Augusti at praetenturam Italias et Alpium expeditione Germanica.- Os antigos cônsules, como os antigos questores e pretores, eram freqüentemente convidados a exercer funções ditas consulares. Essa foi a primeira: uma missão extraordinária. Por isso, quer paracer-nos que Aquilino era um favorito do Imperador

13. legado Augusti pro praetore prouincias Germaniae inferioris.- E a segunda função consular. A Germânia era uma província imperial consular.

14. sacerdoti fetiali.- Temos aqui uma função sacerdotal. Os senadores eram também convidados a exercer funções sacerdotais.

Havia em Roma dois tipos de sacerdócios:

a) sacerdócios individuais: devotados ao culto de uma divindade particular;

b) sacerdócios reunidos: estes se subdividiam ainda em sodalícios e colégios. Entre os sodalícios temos os lupercos, os arvais, os sálios; entre os colégios, os pontífices, os áugures, os feciais, de que fazia parte Antístio Aquilino. Esse colégio de sacerdotes era encarregado da declaração de guerra segundo um rito determinado. Consistia esse em fazer-se, primeiramente, o exame das causas. Depois, pedia-se satisfação. Não sendo obtida, deixavam-se transcorrer 30 dias. Então fazia-se a declaração de guerra; os feciais iam até

(19) - op. cit., p. 244. 
à fronteira da nação com quem os romanos tinham diferenças a ajustar e atiravam um dardo no território inimigo.

A função sacerdotal num texto epigráfico vinha à testa da inscrição, geralmente depois do consulado, raramente antes, embora essa dignidade obtida depois da questura ou da pretura.

A parte final do documento epigráfico informa-nos apenas do nome de quem dedica o monumento a Aquilino - Sexto Márcio Máximo - , dos nobres motivos que o levaram a esse gesto - a gratidão —, dos recursos usados para tanto — os seus próprios ! e da permissão recebida para poder executar tal intento - um decreto dos decuriões (20)

Enfim, como remate desses comentários, podemos acrescentar ainđa dois elementos referentes a essa inscrição: um, que diz respeito à sua localização; o outro, que se refere à sua datação. Com efeito, no que toca à sua localização, podemos saber que essa inscrição é da África, primeiramente porque lemos nela a designação da tribo após o primeiro cognomen (ADVENTVS); depois, ela é de Thibilis, cidade de Numídia como atesta GAFFIOT (21) No que toca à sua datação, sabemos, por um lado, que em $161 \mathrm{~d}$. C. o rei dos partos, Vologeso IV, inicia atividades hostis contra os romanos, o que equivale a uma declaração de guerra (22); sabemos também que em 166 d.c. (março-agosto) os Imperadores Lúcio Vero e Marco Aurélio, de volta da guerra contra os partos, celebram o triunfo (23) Por outro lado, DEGRASSI nos informou (24) que Antístio Aquilino fo cônsul em 166 ou 167 d.C. Devemos acrescentar ainda, conforme vimos acima (25), que o nosso personagem exerceu 2 ou 3 funções consulares. A combinação dessas três informações permite-nos fixar a data provável desta inscrição (e do monumento em que ela foi gravada): ela seria dos anos depois de 169 d.C., presumivelmente dos situados entre 169 e 171

Aí está, pois, um texto epigráfico que, aos poucos, se vai prestando a uma leitura que o torna compreensível e significativo. Além de esclarecer sobremaneira sobre a vida do personagem que está sendo alvo das atenções do dedicante Sexto Márcio Máximo, oferece muitas informações que interessam à história e à civilização dos romanos. Os arcanos da Epigrafia, então, se tornam assim, pouco a pouco, penetráveis e devassáveis. cípios

(20) - Era como se chamavam entre os romanos os senadores dos muni-

(21) - Cf. nota 16 aqui acima.

(22) - GOYAU, op. cit., p. 215.

(23) - Id., ib., p. 218.

(24) - Cf. nota 19 aqui acima.

(25) [ Cf. p. 17 (n⿳⺈ 12 e 13) e p. 16 (n⿳ 10) aqui acima. 